\title{
Successful Treatment of Autoimmune Urticaria with Low-Dose Prednisolone Therapy Administered for a Few Months: A Case Series of 42 Patients
}

\author{
Krisztina Vas $^{\mathrm{a}}$ Anita Altmayer $^{\mathrm{a}}$ Lilla Mihályi $^{\mathrm{a}} \quad$ Edina Garaczi ${ }^{\mathrm{a}} \quad$ Ágnes Kinyóc $^{c}$ \\ Eszter Jakobicz ${ }^{a}$ Sándor Husz ${ }^{a}$ Lajos Kemény ${ }^{a, b}$ Zsuzsanna Bata-Csörgő ${ }^{a}$ b \\ ${ }^{a}$ Department of Dermatology and Allergology, and ${ }^{\mathrm{b}}$ MTA-SZTE Dermatological Research Group, University of \\ Szeged, Szeged, and ' Department of Dermatology, Venereology and Oncodermatology, University of Pécs, \\ Pécs, Hungary
}

\section{Keywords}

Autoimmune diseases · Urticaria

\section{Abstract}

Background: Chronic spontaneous urticaria (CSU) is defined as symptoms of urticaria persisting for 6 weeks or more without obvious cause. Autologous serum skin test (ASST) positivity in patients with CSU is considered to be associated with autoimmune urticaria (AIU). Methods: In this retrospective study we retrieved the medical records of 1,073 urticaria patients seen at the Department of Dermatology and Allergology of Szeged University between January 2005 and February 2014. Forty-two patients ( 36 female and 6 male) met the study criteria by having CSU and giving positive results in the ASST. Our aim was to assess the clinical efficacy and safety of low-dose oral prednisolone therapy administered to patients with antihistamine-refractory ASST-positive CSU for a few months. Patients were given an initial dose ( $40 \mathrm{mg} /$ day) of prednisolone until the complete resolution of the symptoms, usually 7-10 days, and then the dose was gradually decreased, as in other autoimmune diseases. Results: Pred-

\section{KARGER}

(c) 2018 S. Karger AG, Basel

E-Mail karger@karger.com

www.karger.com/drm nisolone therapy lasted for an average of 3.6 months and a complete long-lasting response was achieved in 35 of $42 \mathrm{AIU}$ patients (83.3\%). The follow-up period was at least 36 months (3 years) for each AlU patient; the longest follow-up time was 139 months (11.5 years). None of the patients reported any considerable side effects. Conclusion: Based on our results, we suggest that the use of this treatment could be an alternative for the treatment of AIU. Our present results also highlight the need for other therapies in a small percentage of AIU patients. Our results suggest that AIU represents a transient autoimmunity that can be successfully treated with low-dose steroid therapy administered for a few months.

(c) 2018 S. Karger AG, Basel

\section{Introduction}

Chronic spontaneous urticaria (CSU) has an estimated prevalence of $0.5-1.8 \%$. CSU is defined as symptoms of urticaria usually occurring daily and persisting for 6 weeks or more. In some patients, dermographism or urticaria factitia can also be detected. Patients with urticar- 
Fig. 1. Flowchart of Methods.

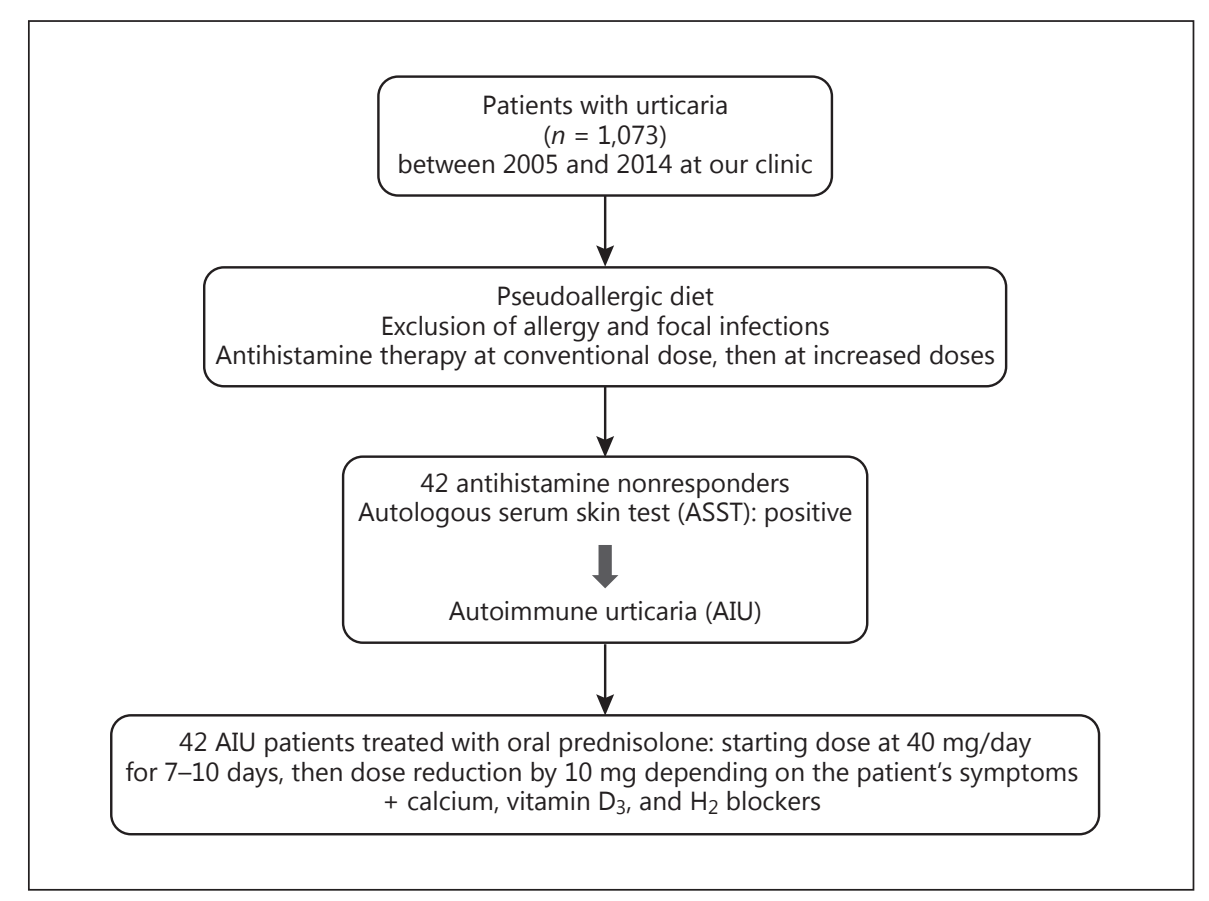

ia may experience concomitant angioedema and intensive itching. Characteristic wheals last for no more than $24 \mathrm{~h}$. The term "chronic spontaneous urticaria" is relatively new, as chronic urticaria has recently been divided into two main groups: "chronic spontaneous urticaria" (CSU) and "chronic inducible urticaria," the latter including the previously termed "physical urticaria" $[1,2]$. A concomitant autoimmune mechanism can be detected in $30-50 \%$ of CSU patients. Autoimmune urticaria (AIU) is not a well-defined condition, but based on some evidence it is accepted that some CSU patients have anti-IgG antibodies against the alpha chain of the high-affinity $\operatorname{IgE}$ receptor $\left(\mathrm{Fc}_{\varepsilon} \mathrm{RI}\right)$ on mast cells and basophil granulocytes and/or against IgE [3-7].

The autologous serum skin test (ASST), an in vivo cutaneous test, is based on intradermal injections of small quantities of autologous serum. It was first described in 1986 as a diagnostic tool for chronic idiopathic urticaria CIU [8-10]. ASST has been widely adopted internationally as a clinical screening method to assess autoreactivity in CSU. In the latest EAACI/GA ${ }^{2} \mathrm{LEN} / \mathrm{EDF} / \mathrm{WAO}$ (2014) guideline, nonsedating $\mathrm{H}_{1}$ antihistamines at the conventional dose is recommended as first-line therapy for CSU, and as second-line therapy it is advised to raise the dose up to 4 times in nonresponding urticaria patients $[1,11]$. If patients are unresponsive to both first- and second-line treatment, the administration of other systemic therapies could be initiated, including azathioprine, leukotriene antagonists, cyclosporine A and/or mycophenolate mofetil, dapsone, TNF- $\alpha$ inhibitors, plasmapheresis, intravenous immunoglobulin, and omalizumab.

In this latest guideline systemic steroid therapy is only recommended for a few days, when patients experience a severe flare. Flares are frequent among CIU patients, therefore these patients often take steroids regularly on an on-off basis, without long-lasting therapeutic effect. Kaplan $[2,12]$ recommended a longer course of prednisolone therapy for chronic idiopathic urticaria (CIU) patients who were unresponsive to antihistamines. Kaplan treated patients with $40 \mathrm{mg} /$ day prednisolone for the first 3 days and then decreased the prednisolone dosage by $5 \mathrm{mg} /$ day gradually, according to the symptoms; when the dosage was down to $25 \mathrm{mg} /$ day, it was further decreased by $5 \mathrm{mg}$ on alternate days. The steroid then was slowly withdrawn by decreasing the dose by $5 \mathrm{mg}$ every $2-3$ weeks. In his experience a 3-month course of such prednisolone therapy was sufficient for healing the patients. Given the autoimmune nature of ASST-positive CSU, we followed the recommendation of Kaplan and used a prolonged course of low-dose oral prednisolone therapy in AIU patients.

The aim of this retrospective study was to assess the efficacy and safety of this therapeutic approach in patients with ASST-positive CSU. 


\section{Methods}

For further details, see the supplementary material (see www. karger.com/doi/10.1159/000484085 for all online suppl. material) [1] (Fig. 1).

\section{Results}

Our 42 AIU patients had symptoms (urticaria, itching, and/or angioedema) for many years and about $1 / 3$ of them have experienced factitious urticaria. Thirty-six of the patients included were women $(85.71 \%)$ and 6 were men $(14.28 \%)$. The mean age at diagnosis was 54 years (26-87 years; median: 56.51 years). In 11 of the 42 patients, anti-thyroglobulin and anti-thyroid peroxidase antibodies were also detected. AIU was associated with urticaria factitia in 12 of the 42 patients. All concomitant diseases of the patients are listed in Table 1. The majority of the patients had had treatment for various types of infections (otorhinolaryngological, dental, urological, gynecological, and Helicobacter pylori infection) during the previous course of their disease.

Out of the 42 patients, 35 (83.3\%) became free of symptoms after the initiation of steroid treatment and their therapy lasted for an average of 3.6 months (1-13 months; Fig. 2). The absolute mean daily dosage was $22.06 \mathrm{mg} /$ day for the responding 35 patients (for patients who took the steroid for less than 4 months it was $0.34 \mathrm{mg} / \mathrm{kg}$ and for those who needed longer treatment it was $0.20 \mathrm{mg} / \mathrm{kg}$ ). The mean daily dosage for the 35 patients was $0.32 \mathrm{mg} / \mathrm{kg}$. None of these 35 patients relapsed during follow-up (Fig. 2); thus among these patients a complete long-lasting clinical remission was achieved. Among the 7 nonresponder patients, some partially responded to the therapy, but they never became completely symptom free. We detected no difference in terms of concomitant diseases between the two groups, responders versus nonresponders (Table 1). The follow-up of the patients after the end of the prednisolone therapy covered a period from 3 to 11.5 years (Fig. 2); In this group of patients we had no serious adverse events; however, 4 patients experienced transitional hair loss and 3 patients gained weight [13].

\section{Discussion}

Patients with CSU may suffer from stigmatization due to their skin lesions (wheals, excoriations due to itching, and angioedema) and the disease often causes consider-
Table 1. Concomitant other diseases in the 42 autoimmune urticaria patients

\begin{tabular}{|c|c|}
\hline $\begin{array}{l}\text { Patient } \\
\text { sex/age, } \\
\text { years }\end{array}$ & Concomitant diseases \\
\hline \multicolumn{2}{|c|}{ Responders $(n=35)$} \\
\hline $\mathrm{F} / 83$ & Vitiligo, polyarthritis \\
\hline $\mathrm{F} / 42$ & Hypothyreosis, urticaria factitia disease (UFD) \\
\hline $\mathrm{M} / 51$ & Helicobacter pylori infection, UFD \\
\hline $\mathrm{F} / 75$ & H. pylori infection \\
\hline $\mathrm{F} / 62$ & $\begin{array}{l}\text { Polyarthritis, Hashimoto thyroiditis, } \\
\text { Norwalk infection }\end{array}$ \\
\hline $\mathrm{F} / 58$ & Colon diverticulosis, UFD \\
\hline $\mathrm{F} / 65$ & Hypothyreosis \\
\hline $\mathrm{F} / 57$ & Hashimoto thyroiditis, rheumatoid arthritis, UFD \\
\hline $\mathrm{M} / 55$ & H. pylori infection, UFD \\
\hline $\mathrm{F} / 75$ & Hashimoto thyroiditis \\
\hline $\mathrm{F} / 60$ & Salmonella infection, morphea \\
\hline $\mathrm{F} / 56$ & $\begin{array}{l}\text { Myelodysplastic syndrome, anemia with } \\
\text { vitamin } B_{12} \text { deficiency, irritable bowel syndrome, } \\
\text { Hashimoto thyroiditis }\end{array}$ \\
\hline $\mathrm{F} / 87$ & Parkinson disease \\
\hline $\mathrm{M} / 40$ & UFD \\
\hline $\mathrm{F} / 43$ & Hashimoto thyroiditis, UFD \\
\hline $\mathrm{F} / 51$ & UFD \\
\hline $\mathrm{M} / 57$ & H. pylori infection \\
\hline $\mathrm{F} / 26$ & Hypothyreosis \\
\hline $\mathrm{F} / 52$ & Hashimoto thyroiditis \\
\hline $\mathrm{F} / 38$ & UFD \\
\hline $\mathrm{F} / 32$ & UFD \\
\hline $\mathrm{F} / 66$ & Hashimoto thyroiditis \\
\hline $\mathrm{F} / 68$ & Hypothyreosis \\
\hline $\mathrm{F} / 66$ & Hashimoto thyroiditis \\
\hline \multicolumn{2}{|c|}{ Nonresponders $(n=7)$} \\
\hline $\mathrm{F} / 50$ & Hashimoto thyroiditis \\
\hline $\mathrm{F} / 40$ & Hypothyreosis, UFD \\
\hline $\mathrm{F} / 40$ & Asthma allergica \\
\hline $\mathrm{F} / 52$ & Hashimoto thyroiditis \\
\hline $\mathrm{F} / 38$ & UFD \\
\hline $\mathrm{F} / 52$ & Hashimoto thyroiditis \\
\hline $\mathrm{F} / 66$ & H. pylori infection \\
\hline
\end{tabular}

able aesthetic and psychological problems. Various therapeutic modalities have been attempted with the aim of improving symptoms of CSU with differing degrees of success, e.g., first- and second-generation antihistamines, leukotriene antagonists, corticosteroids, hydroxychloroquine, dapsone, colchicine, sulfasalazine, cyclosporine, and omalizumab [1]. In everyday practice one of the most common drugs used to treat severe CSU are corticosteroids, although current guidelines do not recommend steroid therapy for prolonged periods of time since its 


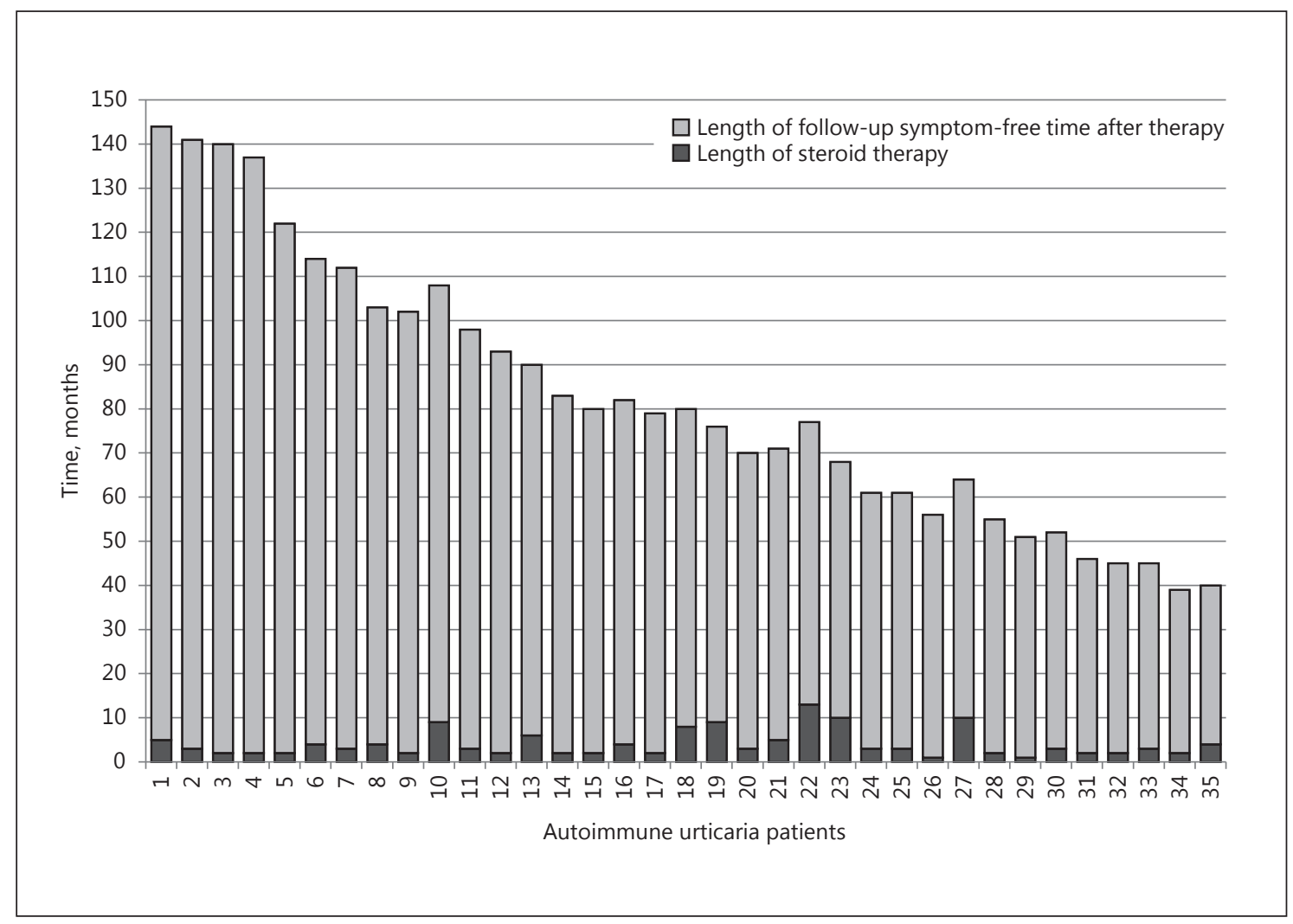

Fig. 2. The length of steroid therapy and the length of follow-up symptom-free period after cessation of therapy for recovered autoimmune urticaria patients $(n=35)$.

side effects could be considerable (hypertension, osteoporosis, cutaneous striae, obesity, cataract, diabetes, etc.). In 1986 Grattan et al. [8] identified AIU among patients with CSU, termed at the time CIU. Many case reports described the rapid efficacy of steroid therapy in AIU, but no complete and long-lasting response has been reported on prednisolone treatment. The EAACI/GA ${ }^{2} \mathrm{LEN} / \mathrm{EDF} /$ WAO guidelines have discouraged the long-term use of oral corticosteroids in chronic urticaria, although evidence for this recommendation was lacking [1].

Systemic corticosteroids can exert influence on multiple levels: they suppress antibody formation, have a strong anti-inflammatory effect, and decrease the production of histamine-releasing factors. AIU is characterized by IgG antibodies against the alpha chain of the highaffinity $\operatorname{IgE}$ receptor $\left(\mathrm{Fc}_{\mathcal{E}} \mathrm{RI}\right)$ on mast cells and basophil granulocytes and/or by antibodies directed against IgE antibodies. These antibodies play a role in mast cell and basophil activation and in the release of both preformed and newly generated mediators (chemokines, cytokines, histamine, serotonin, and leukotrienes) $[5,7,11,14]$. The "gold standard" in vitro methods in AIU detect seruminduced histamine release in basophils (HR assay) and CD63 expression on basophils and mast cells [15-17]. Laboratory tests with high specificity and sensitivity are required for screening patients to detect circulating functional autoantibodies and thereby unequivocally diagnosing AIU among CSU patients. Recently, Lee et al. [18] developed a rapid immunodot method with high specificity to detect autoantibodies against the $\mathrm{F}_{\mathcal{E}} \mathrm{RIa}$ chain in the sera of CSU patients. Unfortunately, these tests are not available yet in everyday clinical practice. Presently, the ASST is used in clinical practice to detect AIU. In AIU, the incidence of anti-thyroid antibodies is higher, and patients should be screened for anti-thyroid peroxidase and anti-thyroglobulin antibodies [19].

Because it has been demonstrated that ASST with undiluted serum could result in nonspecific positive reactions, Husz et al. [20] suggested the use of 1:10 and 1:100 serum dilutions in order to avoid nonspecific test reac- 
tions. In a follow-up study the same workgroup compared the dilution ASST with the CD63 expression test and concluded that dilution did not improve the specificity of the test. However, the severity of AIU correlated well with positive reactions at diluted serum, and therefore it was suggested that using different dilutions of the serum in ASST might serve as a useful indicator of disease severity [21]. The detected autoreactivity, however, does not directly prove the presence of autoantibodies.

Szegedi and colleagues [22] suggested complementing the ASST results with characteristic clinical signs to improve the diagnosis of AIU. The sensitivity (88\%) and specificity (77\%) of ASST complemented with simultaneous clinical symptoms (wheals 6-7 times a week, angioedema and anti-thyroid antibodies) considerably increased the sensitivity (up to 94\%) and specificity (up to $86 \%$ ) of this test.

To our knowledge this is the first report on the use of this few-months-long low-dose oral corticosteroid therapy in a larger AIU study group. The prolonged (average 3.6 months) immunosuppressive therapy proved to be safe and effective in improving the symptoms of patients with positive ASST. Only a few patients experienced light transitional adverse effects during treatment. The circulating autoantibodies responsible for the autoreactive mechanisms in AIU may not be long-lasting and a prolonged oral prednisolone therapy seems to restore the normal balance of the immune system. Although sponta- neous remission is possible, these patients suffer from their symptoms and they need treatment. Based on our results, we consider that prolonged administration of low-dose oral corticosteroids can be a valuable therapeutic alternative in patients with therapy-resistant AIU urticaria. However, our results have also highlighted the need for other therapeutic approaches (e.g., omalizumab) in a small percentage of AIU patients.

\section{Key Message}

Low-dose oral corticosteroid therapy administered for a few months can treat autoimmune urticaria patients.

\section{Acknowledgments}

We would like to thank all our patients with autoimmune urticaria for their collaboration.

\section{Statement of Ethics}

Due to the retrospective nature of the study only local Institutional Review Board approval was requested and granted.

\section{Disclosure Statement}

The authors have no conflicts of interest to disclose.

\section{References}

$\rightarrow 1$ Zuberbier T, Aberer W, Asero R, BindslevJensen C, Brzoza Z, Canonica GW, Church MK, Ensina LF, Gimenez-Arnau A, Godse K, Goncalo M, Grattan C, Hebert J, Hide M, Kaplan A, Kapp A, Abdul Latiff AH, MathelierFusade P, Metz M, Nast A, Saini SS, SanchezBorges M, Schmid-Grendelmeier P, Simons FE, Staubach P, Sussman G, Toubi E, Vena GA, Wedi B, Zhu XJ, Maurer M: The EAACI/ $\mathrm{GA}^{2} \mathrm{LEN} / \mathrm{EDF} / \mathrm{WAO}$ Guideline for the definition, classification, diagnosis, and management of urticaria: the 2013 revision and update. Allergy 2014;69:868-887.

2 Kaplan AP: Urticaria and angioedema; in Middleton E, Reed CE, Ellis EF, Adkinson NF, Yunginger JW, Busse WW (eds): Allergy: Principles and Practice. St. Louis/Baltimore, Mosby, 1998, pp 1104-1122.

3 Gruber BL, Baeza ML, Marchese MJ, Agnello V, Kaplan AP: Prevalence and functional role of anti-IgE autoantibodies in urticarial syndromes. J Invest Dermatol 1988;90:213-217.
4 Horn MP, Gerster T, Ochensberger B, Derer T, Kricek F, Jouvin MH, Kinet JP, Tschernig T, Vogel M, Stadler BM, Miescher SM: Human anti-Fc $c_{\varepsilon} \mathrm{RIa}$ autoantibodies isolated from healthy donors cross-react with tetanus toxoid. Eur J Immunol 1999;29:1139-1148.

5 Niimi N, Francis DM, Kermani F, O’Donnell BF, Hide M, Kobza-Black A, Winkelmann RK, Greaves MW, Barr RM: Dermal mast cell activation by autoantibodies against the high affinity IgE receptor in chronic urticaria. J Invest Dermatol 1996;106:1001-1006.

-6 Fiebiger E, Hammerschmid F, Stingl G, Maurer D: Anti-Fc $c_{\varepsilon} \mathrm{RIa}$ autoantibodies in autoimmune-mediated disorders. Identification of a structure-function relationship. J Clin Invest 1998;101:243-251.

7 Hide M, Francis DM, Grattan CE, Hakimi J, Kochan JP, Greaves MW: Autoantibodies against the high-affinity IgE receptor as a cause of histamine release in chronic urticaria. N Engl J Med 1993;328:1599-1604.
-8 Grattan CE, Wallington TB, Warin RP, Kennedy CT, Bradfield JW: A serological mediator in chronic idiopathic urticaria - a clinical, immunological and histological evaluation. Br J Dermatol 1986;114:583-590.

-9 Sabroe RA, Grattan CE, Francis DM, Barr RM, Kobza BA, Greaves MW: The autologous serum skin test: a screening test for autoantibodies in chronic idiopathic urticaria. Br J Dermatol 1999;140:446-452.

10 Konstantinou GN, Asero R, Maurer M, Sabroe RA, Schmid-Grendelmeier P, Grattan CE: EAACI/GA ${ }^{2}$ LEN task force consensus report: the autologous serum skin test in urticaria. Allergy 2009;64:1256-1268.

11 Kaplan AP: Chronic urticaria: pathogenesis and treatment. J Allergy Clin Immunol 2004; 114:465-474.

12 Kaplan AP: Clinical practice. Chronic urticaria and angioedema. N Engl J Med 2002;346: 175-179. 
13 Liu D, Ahmet A, Ward L, Krishnamoorthy P, Mandelcorn ED, Leigh R, Brown JP, Cohen A, Kim H: A practical guide to the monitoring and management of the complications of systemic corticosteroid therapy. Allergy Asthma Clin Immunol 2013;9:30.

14 Lapolla W, Desai N, English JC 3rd: Clinical utility of testing for autoimmunity in chronic idiopathic urticaria. J Am Acad Dermatol 2012;66:e83-e88.

15 Gyimesi E, Sipka S, Danko K, Kiss E, Hidvegi B, Gal M, Hunyadi J, Irinyi B, Szegedi A: Basophil CD63 expression assay on highly sensitized atopic donor leucocytes - a useful method in chronic autoimmune urticaria. $\mathrm{Br}$ J Dermatol 2004;151:388-396.
6 Szegedi A, Irinyi B, Gal M, Hunyadi J, Danko K, Kiss E, Sipka S, Szegedi G, Gyimesi E: Significant correlation between the CD63 assay and the histamine release assay in chronic urticaria. Br J Dermatol 2006;155:67-75.

17 Frezzolini A, Provini A, Teofoli P, Pomponi D, De Pita O: Serum-induced basophil CD63 expression by means of a tricolour flow cytometric method for the in vitro diagnosis of chronic urticaria. Allergy 2006;61:1071-1077.

18 Lee MF, Lin TM, Liu SW, Chen YH: A rapid method of detecting autoantibody against $\mathrm{Fc}_{\mathcal{E}} \mathrm{RIa}$ for chronic spontaneous urticaria. PLoS One 2014;9:e109565.

19 Irinyi B, Szeles G, Gyimesi E, Tumpek J, Heredi E, Dimitrios G, Adany R, Hunyadi J, Szegedi A: Clinical and laboratory examinations in the subgroups of chronic urticaria. Int Arch Allergy Immunol 2007;144:217-225.
20 Husz S, Mihalyi L, Kemeny L: Diagnostic value of autologous serum skin test in autoimmune urticaria. J Eur Acad Dermatol Venereol 2008;22:1023-1024.

-21 Irinyi B, Gyimesi E, Garaczi E, Bata ZS, Kemeny L, Zeher M, Remenyik E, Szegedi A: Extended diagnostic value of autologous serum skin test and basophil CD63 expression assay in chronic urticaria. Br J Dermatol 2013;168: 656-658.

22 Hajdu K, Irinyi B, Gyimesi E, Kapitany A, Dajnoki Z, Bata-Csorgo Z, Kinyo A, Kiss F, Gaspar K, Szegedi A: A simple, combined test can improve the diagnosis of autoimmune urticaria. Br J Dermatol 2017;177:864-866. 